\title{
A Business Enterprise Resilience Model to Address Strategic Disruptions
}

\author{
Hassan Ahmed Hassan ${ }^{1, *} \&$ Galal Hassan Galal-Edeen ${ }^{1}$ \\ ${ }^{1}$ Faculty of Computers and Information, Cairo University, Egypt \\ *Correspondence: Faculty of Computers and Information, Cairo University, Egypt. E-mail: \\ hassan.hbarakat@gmail.com
}

Received: September 28, 2017 Accepted: October 21, 2017 Published: November 25, 2017

doi: 10.5296/erm.v4i1.13715 URL: https://doi.org/10.5296/erm.v4i1.13715

\begin{abstract}
Resilient business enterprises are able to survive strategic disruptions like technology disruptions and come back as more successful. They succeed because they have resilient characteristics and apply resilience strategies. Based on a case study analysis, this paper builds a business enterprise resilience model that guides the business enterprises to build the resilience capabilities that enable them to survive during strategic disruptions. The proposed model guides the business enterprise to instil in its architecture the design characteristics of resilience that make it ready to respond to disruption. The model uses the resilience strategies of mitigation, adaptation, and transformation and applies them at three enterprise levels; the operating model level, the competitive strategy level, and the business model level. The mitigation strategy moves the operating model to the efficiency frontier. The adaption strategy recovers the enterprise from the impacts of the strategic disruptions. The transformation strategy transforms the enterprise business model totally.
\end{abstract}

Keywords: disruption; strategic disruption, resilience, mitigation, adaptation; transformation, operating model, competitive strategy, business model, resilience characteristic, resilience capability, resilience strategy 


\section{Introduction}

We live in a world of change and disruptions. When they happen, the typical response is, "Who would have thought this will happen?". Whether the economy is strong or weak, competition is fiercer than ever and change comes faster than ever; and if a business wants to survive difficult times, it has to prepare itself to be able to make the right shift at the right time in response to disruptions and changes (Bossidy and Charan, 2002).

Disruptions can be rooted in new technologies, new disruptive business models, emergence of new regulatory and market forces, or changes in the availability of resources (Fiksel, 2003). Some of these disruptions can be game-changing phenomena and cause storms that threaten the business enterprises going through those storms. These kinds of disruptions are called strategic disruptions (Schwartz and Randall 2007). An example of such a strategic disruption is the digital photography technology that threatened the core businesses of the both enterprises, Fujifilm and Kodak (Komori, 2015).

Business enterprises going through these kinds of storms are not equal in their approach to dealing with them and not equal in the results they ended up with after going through the storms; some succeeded while some failed. For e.g. Fujifilm succeeded while Kodak failed facing the digital photography disruption (Komori, 2015). EMC succeeded facing the disruption of the new storage technologies and customer preference change in favour of low tier low cost storage solutions, while Sun Microsystems failed facing the disruption of the technology bubble burst and the associated change in customer preference in favour of open low cost solutions (Bossidy and Charan, 2002).

Successful enterprises build resilience capabilities to prepare for such strategic disruptions using resilient approaches (Hamel and Välikangas, 2003). A resilient approach is not concerned with stabilizing business enterprises quickly under small shocks, but rather, it is concerned with making business enterprises continuously survive large strategic disruptions in the long term. A resilient approach is concerned with surviving different strategic disruptions through continuously monitoring, interpreting, and adapting to sustainable trends that cause business enterprises to permanently lose the profitability and growth of their core businesses (Hamel and Välikangas, 2003).

\subsection{The Concept of Resilience}

Resilience (with its roots in the Latin word resilio) means to adapt and "bounce back" from a disruptive event (Longstaff, Armstrong et al., 2010). Similarly, it is the capacity of a system to absorb disturbance, undergo change, and retain the same essential functions, structure, identity, and feedbacks (Holling, 1973).

(Holling, 1973) differentiated between two types of resilience, ecological resilience and engineering resilience. In the view of ecological resilience, the system seeks survival facing large disruption. While, in the view of engineering resilience, the system seeks stability facing small disruptions. In the same way, (Fiksel, 2003) differentiates between two types of systems, resistant system and resilient system. What (Fiksel, 2003) called resistant system, is a typical of engineered highly controlled system. Resistant systems are designed to resist small disruptions 
and return back in a very short time to their equilibrium states, but they are not designed to survive large disruptions. A bridge would be an example of an engineered highly controlled system; the bridge can face small perturbation like wind or earthquake and return back in a short amount of time to its equilibrium state. In the other hand, what (Fiksel, 2003) called resilient system, is a system that is adaptive and transformative. When a resilient system faces large disruption, it does not necessarily return to a specific stated equilibrium state, but it is capable to survive and keep its structure and services. In a resilient system like human society, people may have diverse livelihoods that give them options for responding to change. In the western Indian ocean region, for e.g., fishers from households with more diverse livelihood portfolios that included non-fishing activities were more able to consider leaving a fishery that was in decline (Cinner, McClanahan et al., 2012). Not only does such livelihood flexibility increase the resilience of individual households, it also reduces the pressure on the parts of the system producing a particular service, thereby enhancing the resilience of that system service (Ellis 2000).

Since business enterprises are complex adaptive systems that are subject to large disruptions from their internal and external environments (DOOLEY, 2002), they lend themselves more to the view of ecological resilience than to the view of engineering resilience, when we analyze situations in which these business enterprises face large and sustainable strategic disruptions. In these kind of situations, business enterprises are exposed to disruptive forces that threaten the identity and very existence of these enterprises, and the biggest concern is to survive or to persist using the concepts of ecological resilience (Holling, 1973).

Within the ecological resilience view, a system like a business enterprise, can exist in one of several basins of attractions called regimes. The system shifts from one basin of attraction or regime to another if it passes the threshold of a controlling variable (Holling, 1973).

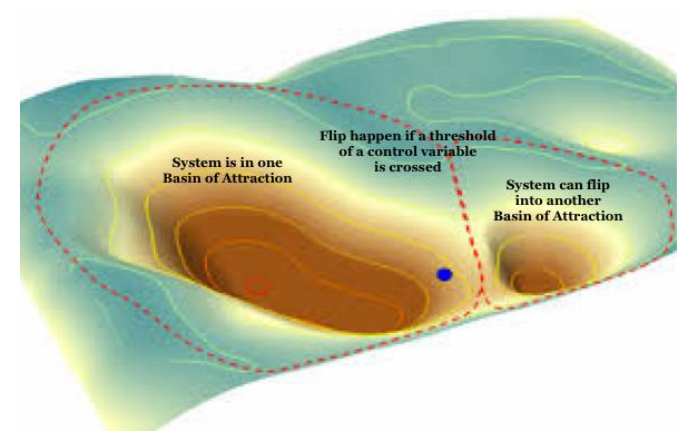

Figure 1. Basin of Attractions

A threshold of a controlling variable, is the level or amount of a change of that controlling variable, that causes a change in a critical feedback, causing the system to self-organize along a different trajectory towards a different attractor (Walker and Meyers, 2004). In spite that complex adaptive systems like business enterprises are affected by many variables; they are usually driven by only a handful of key controlling variables (Walker and Meyers, 2004). This 
is an important concept that is used to create and execute strategies to respond to disruptions. For e.g., if we want to prevent the system from flipping into another regime, we should prevent crossing the thresholds of the systems' controlling variables.

\subsection{Research Objective}

Strategic disruptions are game-changing phenomena. They do not happen very frequently, but when they occur, the rules of the game that were previously in place no longer apply (Schwartz and Randall 2007). Strategic disruptions could include the introduction of new technologies, the emergence of new regulatory and market forces, or changes in the availability of resources (Fiksel, 2003). When a business enterprise faces a strategic disruption, its core business crumbles and its very existence is on the brink. This is clear for e.g. in the case of Fujifilm facing the disruption of the digital age (Komori, 2015).

Business enterprises need to continuously anticipate and adjust to trends that can permanently impair the earning power of their core businesses. They need to build resilience capabilities to prepare for strategic disruptions. They also need to develop strategies and execute actions when being inside the storms of these strategic disruptions. We call business enterprises that monitor trends, build resilient capabilities, and execute resilience strategies; by resilient business enterprises.

There is a strong need to understand, learn, and develop a resilience model that captures how successful resilient business enterprises prepare for and act during strategic disruptions in a way that ensures survivability of these resilient business enterprises. This need is clear when we look at the difference of results between Fujifilm and Kodak. Both enterprises faced the same disruption, the digital photography that impacted their core film businesses. After the storm, Fujifilm became a much more successful company with diversified business, ranging from optical devices to radiopharmaceuticals, while Kodak filed for bankruptcy in 2012 (Komori, 2015). Both companies saw the digital disruption and executed strategies in responses to it, but one succeeded and the other failed. This points clearly to a gap in having a clear resilience model that stitches together strategies and actions in a way that enables the enterprise to survive the storm successfully. This work aims at building a business enterprise resilience model that addresses this gap by learning from a successful resilient business enterprise.

\section{Methodology}

We conducted a search into the strategies and actions taken by Fujifilm enterprise that made it successfully survive the disruption of the digital photography and the digital age in general. The digital disruption impacted Fujifilm's photo film core business and all its associated products and services (Gavetti, Tripsas et al., 2007). Facing the digital disruption and its associated decline in the global demand for colour film, Fujifilm responded by a series of strategies and actions with specific time patterns and with specific sequence and mix. We searched those strategies and actions, categorized them, looked at what was effective and what was not, looked at what was there for those that worked to succeed, and investigated the 
relations between these strategies and action.

The main text we analysed is the book written by the Fujifilm president (Komori, 2015) describing Fujifilm's view of the disruption and articulating the different strategies and action taken in response to the disruption. In addition to the main text, we conducted several online search queries of "Fujifilm digital crisis", "Fujifilm inside the storm", "Fujifilm vs Kodak", and "Fujifilm survived", to collect the articles written about the digital disruption that impacted Fujifilm and how it responded to the disruption. We filtered these articles to focus only on those that articulated the specific strategies and actions taken by Fujifilm in response to the disruption, along with the viewpoints of what made those strategies and actions succeed. Articles that were not focusing on the specific strategies and actions taken by Fujifilm were not selected. This method resulted in a book and a set of articles that constitute the text for the qualitative analysis as shown in Table 1.

Table 1. Summary of the Analysed Text

\begin{tabular}{l}
\hline Title of Text \\
\hline Innovating out of crisis: How Fujifilm survived (and Thrived) as its core business \\
was vanishing (Komori 2015) \\
Fujifilm: A second foundation (Gavetti, Tripsas et al. 2007) \\
Kodak's downfall wasn't about technology (Anthony 2016) \\
How Fujifilm survived - Sharper Focus (K.N.C. 2012) \\
FUJIFILM'S "MOMENT": DISRUPTION, ADAPTATION AND HEALTH \\
SYSTEM TRANSFORMATION (Johnson 2015) \\
How Fujifilm survived the digital age with an unexpected makeover (Ng 2017)
\end{tabular}

\section{Results}

We conducted a directed content analysis (Hsieh and Shannon, 2005) to the text. Guided by the ecological resilience theory, we began by a set of initial coding categories. We coded the text based on this initial set of coding categories, but any text that could not be categorized with the initial coding scheme would be given a new code (Forman and Damschroder, 2007).

We used the directed content analysis method because we believe that, the ecological resilience theory is a powerful theory to explain how complex adaptive systems like business enterprises (DOOLEY, 2002) behave under large perturbations (Walker and Meyers, 2004). The ecological resilience theory will give a structure to the resilience approach through providing relationships between concepts and metaphors to explain behaviour of complex adaptive concepts under large perturbations. Figure 2 shows the coded categories. 


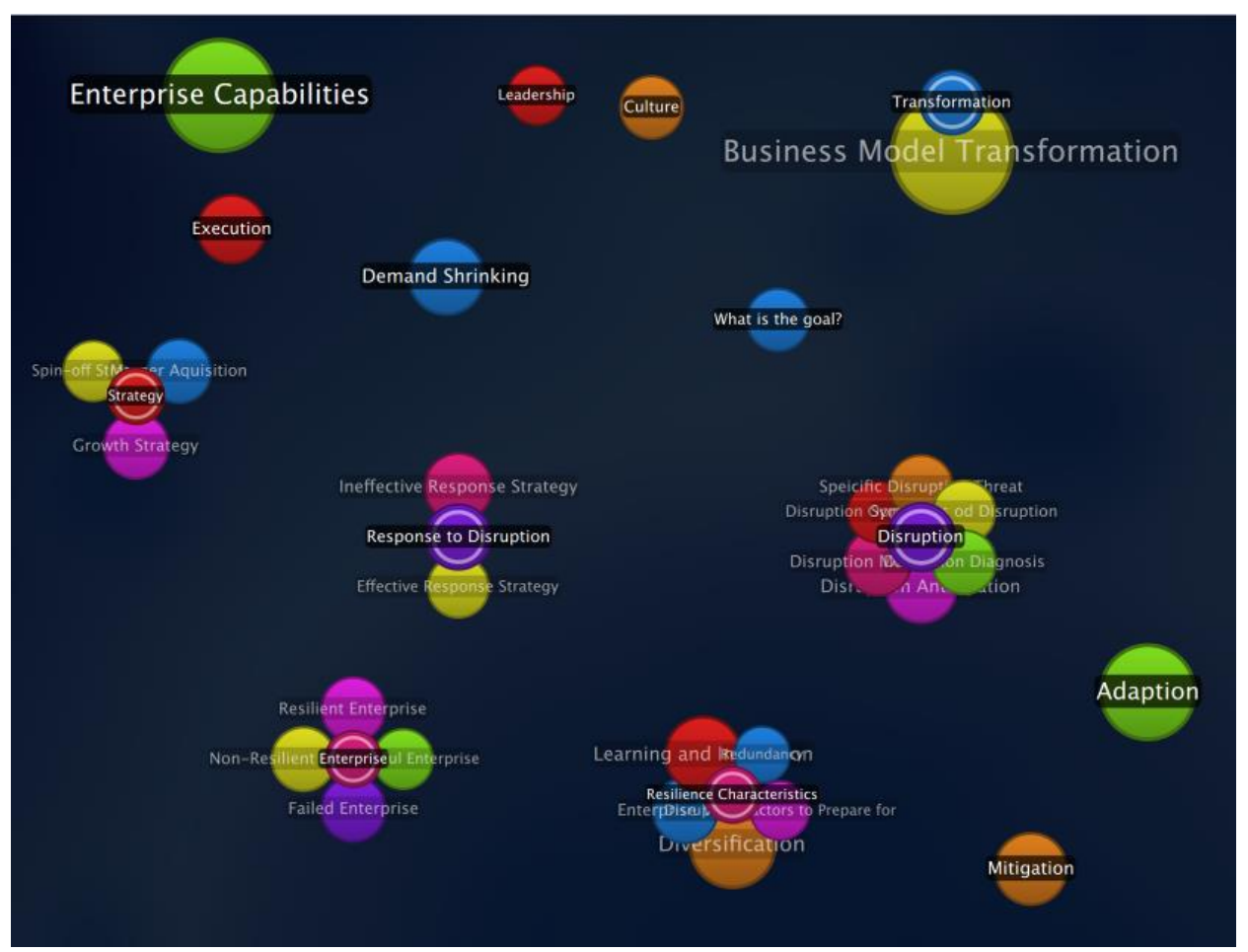

Figure 2. Categories and Themes

Table 2 shows the list of categories and their parents:

Table 2. Categories List

\begin{tabular}{lll}
\hline Category & Parent & Number of coded text segments \\
\hline Demand Shrinking & & 15 \\
Disruption & & Parent (9) \\
Disruption Anticipation & Disruption & 12 \\
Disruption Monitoring & Disruption & 8 \\
Disruption Opportunities & Disruption & 4 \\
Specific Disruption Threat & Disruption & 6 \\
Symptoms of Disruption & Disruption & 5 \\
Disruption Diagnosis & Disruption & 6 \\
Enterprise Capabilities & & 43 \\
Mitigation & & 12 \\
Adaption & & 30 \\
Enterprise & & Parent \\
Failed Enterprise & Enterprise & 6 \\
Non-Resilient Enterprise & Enterprise & 6 \\
Resilient Enterprise & Enterprise & 3 \\
Successful Enterprise & Enterprise & Parent \\
Strategy & & 7 \\
Growth Strategy & Strategy & \\
\hline
\end{tabular}


Spin-off Strategy

Merger/Acquisition

Transformation

Business Model Transformation

Response to Disruption

Effective Response Strategy

Ineffective Response Strategy

Resilience Characteristics

Diversification

Learning and Innovation

Disruption Factors to Prepare for

Enterprise Values

Execution

Leadership

Culture

What is the goal?

Total Number of Coded Text

Segments

\section{Discussion}

We organized the categories and themes into four components that composed what we called a business enterprise resilience model. $\mathrm{x}$ (figure 3). The following discussion shows how the business enterprise resilience model organize the actions and strategies that a resilient business enterprise prepares for and acts during strategic disruptions.

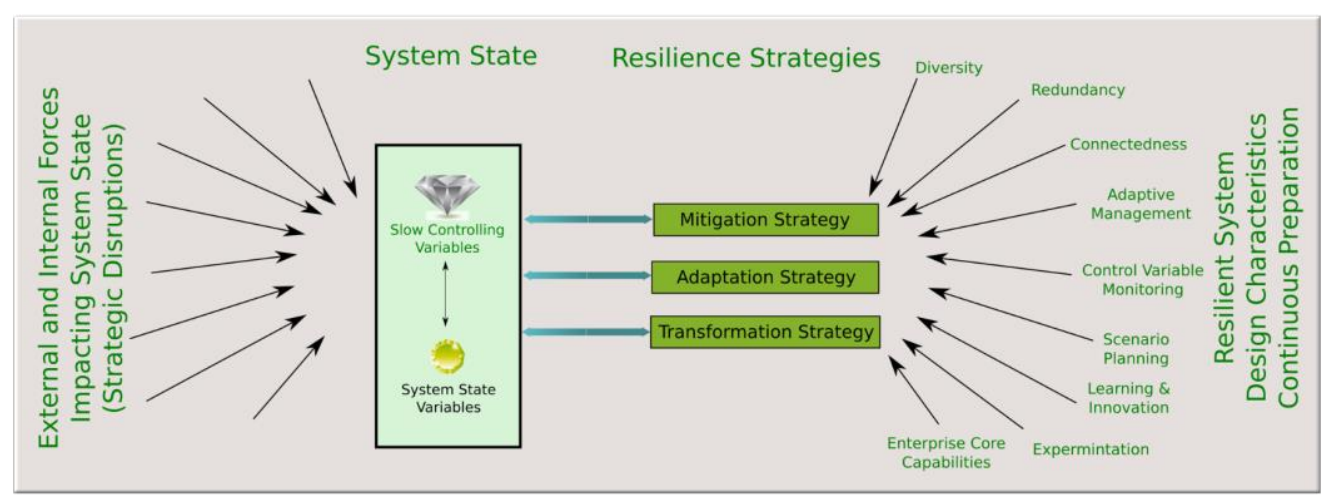

Figure 3. Business Enterprise Resilience Model 


\subsection{Strategic Disruptions}

The first component of the model as shown in figure 2 is the external and internal forces that may have the dynamics to create strategic disruptions. We live in a world of change and disruptions. Whether the economy is strong or weak, competition is fiercer than ever and change comes faster than ever; and if a business wants to survive difficult times, it has to understand the dynamics of the external and internal forces, anticipate trends that may cause strategic disruptions, prepare itself to respond, then make the right shift in response to these strategic disruptions (Bossidy and Charan, 2002).

Out of the many disruptions that businesses face, a strategic disruption has three key elements that differentiate it from the run-of-the-mill disruptions that are so common in today's complex world (Schwartz and Randall, 2007): It has an important impact on an organization; because it challenges the conventional wisdom "the official future," it is difficult to convince others to believe that the surprise is even possible; and it is hard to imagine what can be done in response.

Strategic disruptions are game-changing phenomena. They do not happen very frequently, but when they occur, the rules of the game that were previously in place no longer apply (Schwartz and Randall, 2007). Examples of strategic disruptions are; introduction new technologies, emergence of new regulatory, entrance of new competitor, introduction of new business model, and changes in the availability of resources (Fiksel, 2003).

\subsection{System State}

The second component of the model as shown per figure 3 is the system state. According to the theory of ecological resilience, the system state is represented by a basin of attraction that represents the current regime of the system. The basin of attraction is a stable domain in which the system has specific characteristics and delivers specific services (Folke, Carpenter et al., 2010). Complex adaptive systems like business enterprises are affected by many variables, however they are usually driven by only a handful of key controlling variables. When the states of these controlling variables are within specific ranges, the feedback forces controlling the behaviour of the system ensure that it is in a specific regime. The ranges are bounded with is called thresholds. When the states of the controlling variables move outside the specific ranges (meaning, they cross the thresholds), the feedback forces controlling the behaviour of the system change to another regime. This happens suddenly and in very short time. After crossing the controlling variables thresholds, it is usually extremely difficult for the system to return back to its original regime (Walker and Meyers, 2004).

In the case of business enterprises, the most critical controlling variable is the total demand of the products and services of their core businesses. When the total demand shrinks to the point that the control variable threshold is crossed, the regime of the business enterprise shifts to an unprofitable basin of attraction, from which the business enterprise will not be able to recover. For e.g. Kodak and Fujifilm suffered from a devastating decline total demand for the products and services of its film core businesses when the digital age disruption gained its momentum.

That is why, the enterprise has to monitor the trends and understand the forces that will impact 


\section{Macrothink}

the controlling variable of the total demand. The business enterprise can do actions that either mitigate the impact on the total demand variable, recover after the impact happens, and transform itself intentionally to a totally new profitable regime.

\subsection{Design Characteristics of Resilient Systems}

The third component of the model as shown in figure 3 is the set of design characteristics that makes the enterprise, resilient enterprise. We can design business enterprises to better absorb disruptions, operate under a wider variety of conditions, and shift more fluidly from one circumstance to the next (Hills, 2000). These characteristics enable the enterprise to apply the required resilience strategies to survive and persist when facing strategic disruptions (Reeves, Levin et al., 2016). Figure 4 shows these design characteristics.

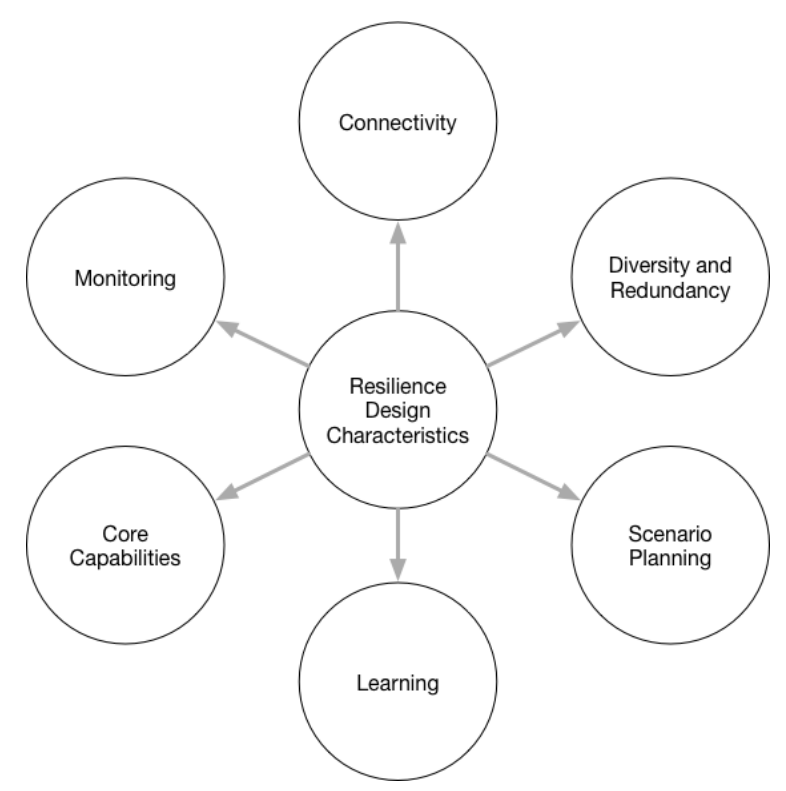

Figure 4. Design Characteristics of Resilient Systems

Diversity and redundancy in systems provide options for responding to change and disturbance and for dealing with uncertainty and surprise (Walker, Gunderson et al., 2006). It is specifically response diversity, in combination with functional redundancy, that is important for maintaining system services in the face of disturbance and ongoing change (Walker, Gunderson et al., 2006).

Connectivity in systems generally facilitates the flow of energy, material or information necessary for the resilience of system services. The strength and structure of connectivity may safeguard system services against a disturbance either by facilitating recovery or by constraining locally the spread of a disturbance (Nyström and Folke, 2001).

Control variables monitoring and management requires understanding the forces that underlie the different systems configurations and their associated levels of the these control variables 
(Holling, 2001). If the current system configuration is a preferable regime, the strategy typically focuses on avoiding changes in feedbacks and controlling variables that could cause the system to cross a critical threshold into another regime. On the other hand, if the system is locked into an undesirable regime, it may be necessary to weaken the feedbacks that keep it there, to restore a previous regime or transform the system to an entirely new regime (Folke, Carpenter et al. 2010). One example of a resilient enterprise is EMC, which faced a decline in the total demand of its high tier, expensive, and proprietary storage solution. EMC responded by reinforcing counter forces that kept the total demand checked within its threshold, it did this by increasing its customer base by selling lower cost, lower tier, and open solutions (Bossidy and Charan, 2002). Fujifilm transformed itself and shifted to a new regime of being a new diversified business in which its film core business became a small fraction of its total business (Komori, 2015).

A business enterprise cannot be resilient against all possible types of disruptions since this is economically impossible (May, Levin et al., 2008). The enterprise has to find a way to understand the uncertainties that may define the trajectory of its future, then design the resilience characteristics that make itself resilient against these certainties. Scenario planning is a tool that can help with this regard (Schoemaker, 1991). Scenario planning is a disciplined method for articulating the possible futures that may evolve taking in consideration the most critical uncertainties that drive these scenarios (Schoemaker, 1991).

Knowledge of complex systems like business enterprises is always partial and incomplete, so for the system to be resilient, it must have the capacity for continuous learning (Holling, 1996). Creating, testing and designing experiments to explore alternative options is an important way to support learning, innovation, and enhance the resilience of the enterprise.

Resilient business enterprises build in-house core capabilities that are valuable, rare, inimitable and non-substitutable (Barney, 1991). These core capabilities will be the base for transformation based on diversifying their uses and applications. For example, Fujifilm's capability in nanotechnology for placing chemicals onto film, was carried over to applying cosmetics to facial skin.

\subsection{Resilient Strategies}

(Folke, Carpenter et al., 2002) introduced three kinds of resilient strategies; mitigation, adaptation, and transformation. They are used by systems based on the available time and level of control over the disruption as shown in figure 5. 


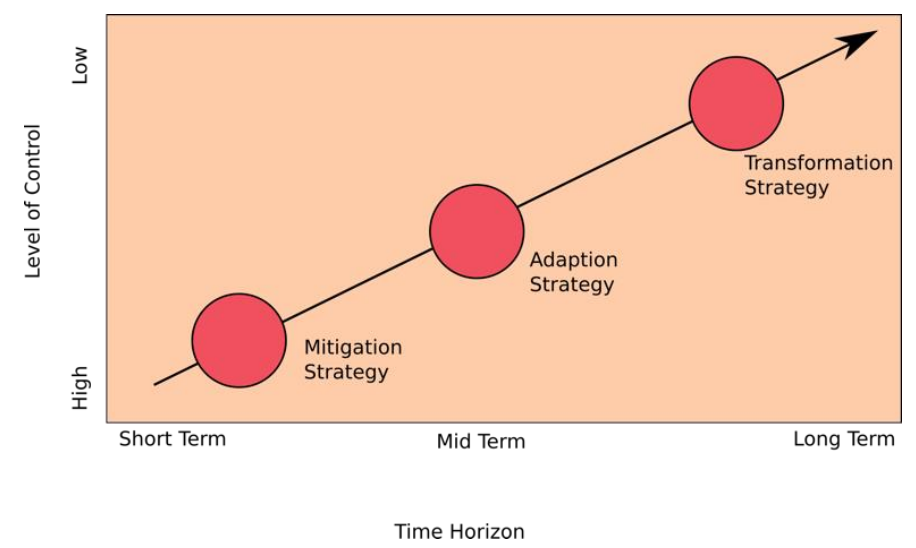

Figure 5. Resilient Strategies

Mitigation strategy (figure 6) is the capacity to initiate counter forces to keep the control variables checked within their thresholds or delay crossing these thresholds. This will prevent or delay the expected impactful changes in the structure and critical feedback which causes the system to flip into an alternate undesirable stability regime of that system (Walker and Meyers, 2004). As an example, Fujifilm launched a research on raising the film's level of light sensitivity so that a flash was unnecessary. Also, the grain was made even smaller, increasing resolution. The goal was to produce an image from photo film that was far superior to anything from digital technology. Fujifilm did this to extend the life of its photosensitive materials business by raising analog image quality to a level beyond digital reach. This strategy acted as a counter force and kept the total demand of the photo film at a reasonable level, giving Fujifilm precious needed time to launch other strategies (Komori, 2015).

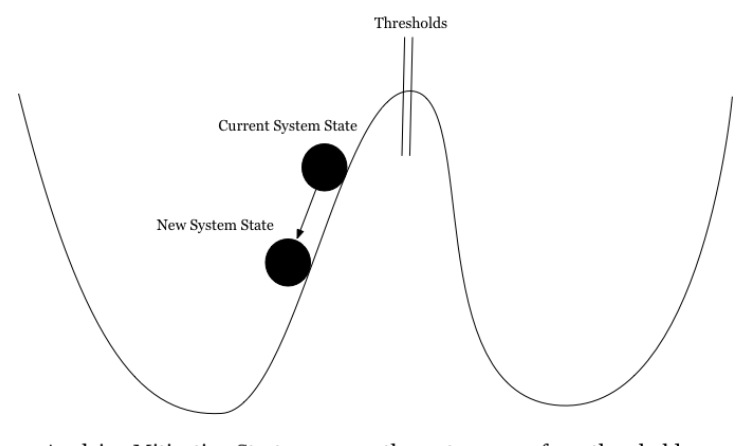

Applying Mitigation Strategy moves the system away from thresholds

Figure 6. Mitigation Strategies

Adaptation strategy (figure 7) in this context represents the capacity to adjust responses to changing external drivers, controlling variables and internal processes, and thereby allow for return to the current trajectory (stability domain). It takes the system into a temporary recovery state in which adaptive responses work to cross back the control variables thresholds, return 


\section{Macrothink}

back to the current regime, and try to move away from the control variables thresholds (Walker and Meyers, 2004).

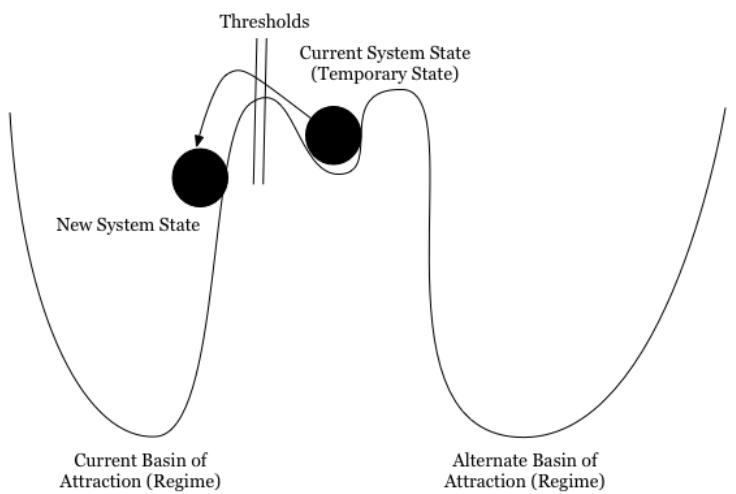

Applying Adaptation Strategy moves the system back after crossing thresholds

Figure 7. Adaptation Strategies

Transformability (figure 8) is the capacity to cross thresholds into new development trajectories. It is the capacity of the system to literally transform itself into a different kind of system. Transformability becomes very important when a system is in a stability regime that is considered undesirable, and it is either impossible, or getting progressively harder and harder, to engineer a 'flip' to the original or some other regime of that same system. The system will have a different identity. (Folke, Carpenter et al., 2010).

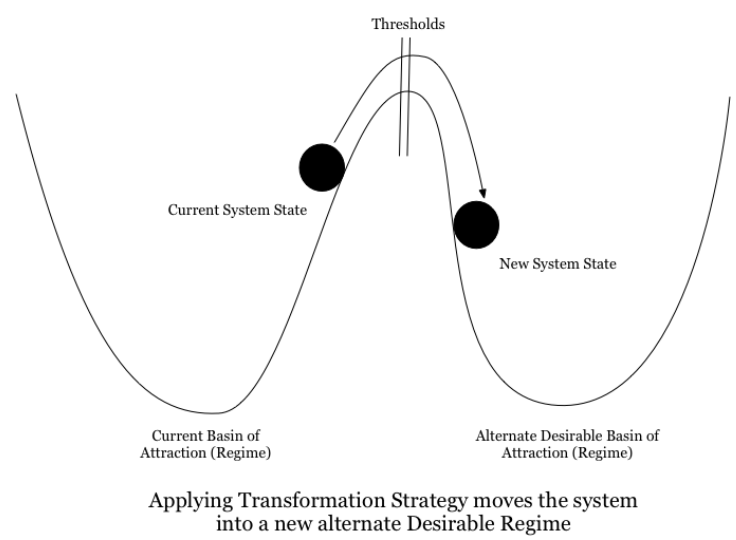

Figure 8. Transformation Strategies

Resilience strategies are implemented through changes to the architecture of business enterprises and through strategies that are executed by these business enterprises in their 
markets. Changes to the business enterprise happens at three cascaded configuration levels; the business model level, the competitive strategy level, and the operating model level (Teece, 2010). Each level gives a context to the next level as per figure 9.

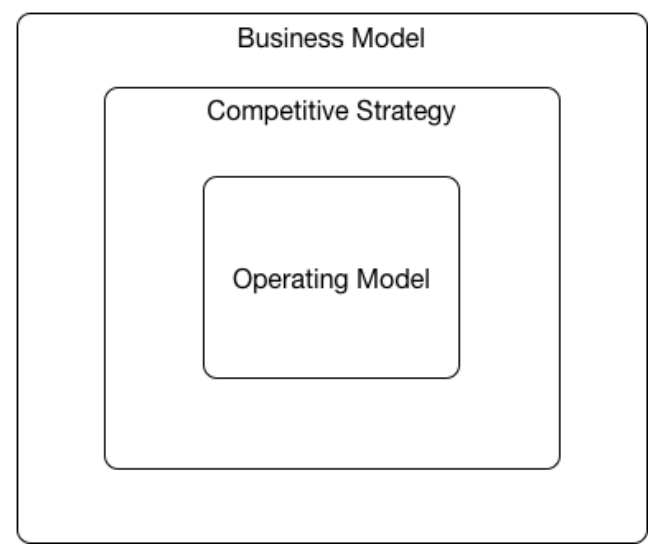

Figure 9. Enterprise Configuration Levels

The first, foundational, and highest level is the business model level. Whenever a business enterprise is established, it either explicitly or implicitly employs a particular business model that describes the design or architecture of the value creation, delivery, and capture mechanisms it employs. The essence of a business model is in defining the manner by which the enterprise delivers value to customers, entices customers to pay for value, and converts those payments to profit. It thus reflects management's hypothesis about what customers want, how they want it, and how the enterprise can organize to best meet those needs, get paid for doing so, and make a profit (Teece, 2010). A good business model yields value propositions that are compelling to customers, achieves advantageous cost and risk structures, and enables significant value capture by the business that generates and delivers products and services. Designing a business model correctly, and figuring out, then implementing commercially viable architectures for revenues and for costs are critical to enterprise success (Fisken and Rutherford, 2002).

The second level is the competitive strategy level, which is the creation of a unique and valuable position, involving a different set of coordinated activities (Porter, 1985). Selecting a competitive strategy is a more granular exercise than designing a business model (Chesbrough and Rosenbloom, 2002). Competitive strategy protects the competitive advantage that results from the design and implementation of business models as it creates various isolating mechanisms to prevent the business model from being undermined through imitation by competitors or disintermediation by customers (Harreld, O'Reilly et al., 2007).

The third level is the operating model level, which depicts how the business operates through its process architecture. Business processes describe the work performed by all resources involved in creating outcomes of value for customers and other stakeholders. The operating model depicts how the business model and business strategy are operationalized and executed. 
Business enterprise's operating model captures the work done by the enterprise on a daily basis (Winter and Fischer, 2006).

When a resilient business enterprise faces a strategic disruption that impacts a critical controlling variable like the total demand for its products and services or the ability of the enterprise to meet this total demand, it applies a mix of the resilience strategies of mitigation, adaptation, and transformation. Each of these three resilience strategies has a mission and delivers specific types of outcomes within the large scheme of responding to the strategic disruption. Each of these three resilience strategies is implemented through changes at one or more of the three enterprise configuration levels; the business model level, competitive strategy level, and business model level as shown in figure 10.

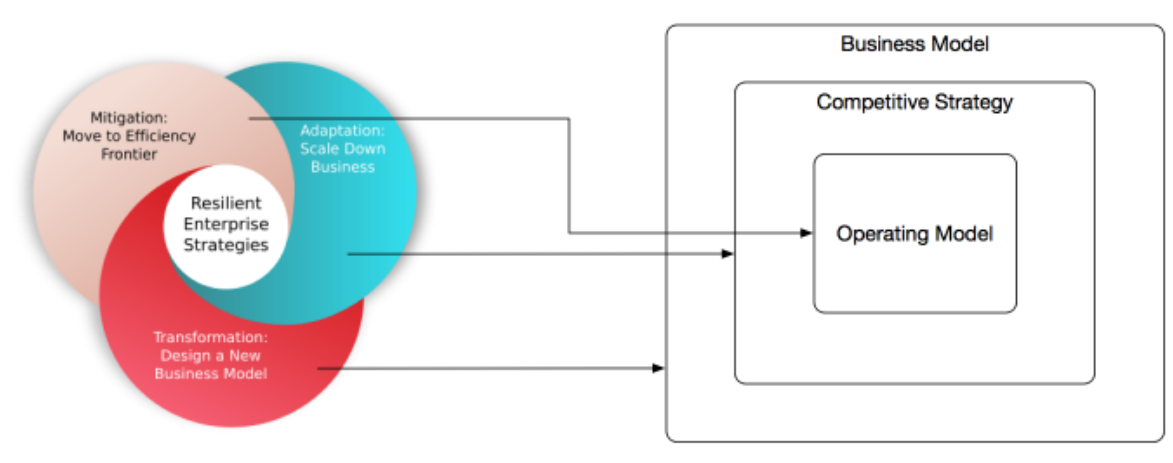

Figure 10. Resilience Strategies Used by Resilient Enterprises Facing Strategic Disruptions

The mitigation strategy in the context of addressing strategic disruptions by business enterprises, is applied to either reverse or at lease slow down the impact of a strategic disruption over the critical controlling variables of a business enterprise. The resilient business enterprise applies the resilience mitigation strategy through changing the operating model of the business enterprise. Taking the operating model of the business enterprise to its efficiency frontier to maximize the return on business operations, reduce cost, and ensure resources availability is the primary intention of the mitigation strategy. Changing the operating model in this way has two outcomes; the first is the reverse or slowdown of the negative impact of the strategic disruption over the critical controlling variables, and the second is accumulating more resources that will be needed if a subsequent transformation phase will happen.

The adaptation strategy in the context of addressing strategic disruptions by business enterprises, is applied to recover from the impact of a strategic disruption over the critical controlling variables of a business enterprise. This happens after the negative impact takes momentum putting the current regime of the business enterprise in a very critical position. Usually resilient business enterprises do not wait that far unless there is no way to reverse the trend and they deal with this by smoothly phasing out or shrinking the current regime, and in parallel launches a transformation strategy. The resilient business enterprise applies the resilience adaptation strategy through changing the competitive strategy level of the business 
enterprise. The resilient business enterprise applies a "scaling down" strategy to match the impact of the strategic disruption over the critical controlling variable. The goal of the adaptation strategy is to survive the impact, minimize cost, liquidate the released resources and add them to the resource base needed during the transformation strategy phase.

The transformation strategy in the context of addressing strategic disruptions by business enterprises, is applied to deliberately design a switch of the business enterprise to a new regime. The resilient business enterprise applies the resilience transformation strategy through changing the business model level of the business enterprise. The activities done within both the mitigation and adaptation strategies enable the resilient enterprise to survive the impact and accumulate the required resources for the transformation strategy to work. The goal of the transformation strategy is for the resilient enterprise to redesign its business model by reconfiguring its accumulated resources and capabilities and by using its stock of innovations and experiments and apply them to create and deliver different kinds of values to different areas in the market place. The transformation strategy shakes the very foundation of the enterprise, transform it into a different kind of an enterprise, and change its identity (Folke, Carpenter et al., 2010).

\subsection{Fujifilm Application of the Resilience Strategies}

Fujifilm is an enterprise that faced the strategic disruption of the digital age. Its main competitor Kodak also knew that the winds of the digital age were blowing, but at the end of storm, Fujifilm transformed itself as a new diversified enterprise while Kodak failed. Fujifilm anticipated the future and was quick to adapt. Figure 11 summarizes the resilience model of Fujifilm, that explains how it transformed itself in response to the strategic disruption of the digital age.

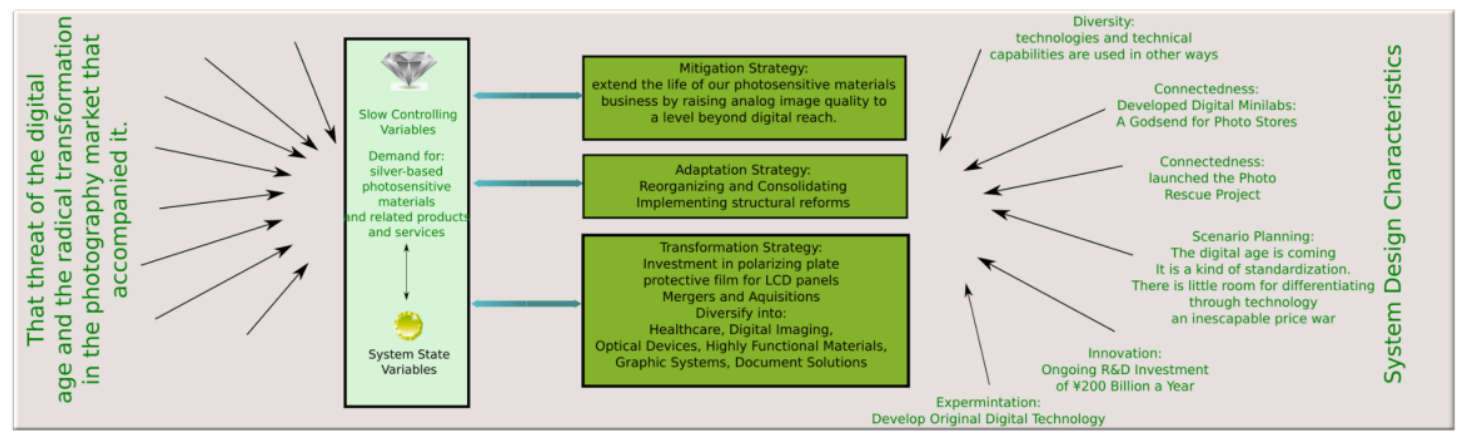

Figure 11. Resilience Model for Fujifilm

The strategic disruption - the digital age

Fujifilm faced a big threat that would require a fundamental change in the organization. That threat was the digital age and the radical transformation in the photography market that 
accompanied it.

By the beginning of the 1980s, industry watchers were already predicting that silver-based photosensitive materials would one day be an endangered species. In Fujifilm's principal imaging fields: photography, printing and medical, the first signs of digitalization had already begun to appear. The digital age drew steadily nearer and nearer to Fujifilm's core (Komori 2015).

Fujifilm anticipated that the digital age would be different. It would be a world in which Fujifilm's proprietary technical expertise; the photography technology built up over the years, including high-precision coating of chemicals on film; would no longer be relevant (Komori 2015).

The Mitigation Strategy - Move to the Efficiency Frontier

The mitigation strategy was to extend the life of the photosensitive materials business by raising analog image quality to a level beyond digital reach. The fact was that photosensitive materials using a silver halide base still had a good deal of room for improvement. Fujifilm launched research on raising the film's level of light sensitivity so that a flash was unnecessary. Also, the grain was made even smaller, increasing resolution. The goal was to produce an image from photo film that was far superior to anything from digital technology.

The mitigation strategy of extending the life of the photosensitive materials business delayed the impact of the approaching digitization strategic disruption. The impact of decreasing demand was much of a much slower rate than the industry, and it gave Fujifilm the critical needed time to redesign and reorganize.

The Adaptation Strategy - Scale Down

The photographic film business is built atop a giant industry infrastructure. Fujifilm had large-scale factories in Japan, the United States, and the Netherlands, as well as photofinishing labs in one hundred fifty locations throughout the world. Maintaining facilities on this scale was extremely costly.

Once sales started to drop, they dropped without stopping, and deficits led to more deficits. All these costs had to be reduced without a second thought. Fujifilm decided not to abandon the photographic film market totally, but instead it reorganized the business to ensure a stable flow of profit. This necessarily involved some serious downsizing to create a smaller, more flexible business that was in keeping with current demand. Fujifilm implemented serious structural reforms, in which it reorganized the photographic film business, including Fujifilm's global, large-scale manufacturing plants and sales organizations, research centers, and photofinishing labs (Komori, 2015).

The Transformation Strategy - Business Model Transformation

Fujifilm anticipated that, the digital world is a world of ruthless price-cutting. Even though Fujifilm had succeeded in producing a digital camera and had come to terms with digitalization, those milestones were not enough to capture back the former profitability of the film market. 
Fujifilm had to create a highly profitable core business in its place.

Fujifilm developed an inventory of Fujifilm's technical stock, its technological seeds. It compared these seeds with the demands of international markets. It then mapped its technology seeds to markets (Komori, 2015).

The enterprise applied its technical capabilities and diversified into the businesses of Digital Imaging, Optical Devices, Highly Functional Materials, Graphic Systems, Document Solutions, and Healthcare (Komori, 2015).

\section{Conclusions and Future Work}

This study introduces a resilient model that explains how resilient business enterprises survive strategic disruptions. The model proposes to design the enterprise for resilience by applying the design characteristics of resilience including diversity, redundancy, connectedness, control variables monitoring, scenario planning, learning, and developing core enterprise capabilities. Building the enterprise for resilience prepares it to execute the resilience strategies. The resilience model suggests monitoring the trends and anticipate potential strategic disruptions.

The resilience approach uses the resilience strategies of mitigation, adaptation, and transformation and execute them at the right times and in the right combinations in a way that enables resilient business enterprises to face, survive and thrive during deep strategic disruptions. The model applies these strategies at three levels; the operating model level, the competitive strategy level, and the business model level. The mitigation strategy moves the operating model to the efficiency frontier. The adaption strategy scales down the business and recovers from the impacts of the strategic disruptions. The transformation strategy changes the business model of the business which transforms the enterprise into a new identity.

One area of future work is to categorize the strategic disruptions and to create a model for understanding the forces that underlie their dynamics. Another area of future work is to investigate an approach for how to change the enterprise configuration at the three levels; the operating model, the competitive strategy, and the business mode.

\section{References}

Anthony, S. (2016). Kodak's downfall wasn't about technology. Harvard Business Review.

Barney, J. B. (1991). Firm Resources and Sustained Competitive Advantage. Journal of Management, 17, 99-120. https://doi.org/10.1177/014920639101700108

Bossidy, L., \& R. Charan. (2002). Execution: The Discipline of Getting Things Done Crown Business. New York.

Chesbrough, H., \& R. S. Rosenbloom. (2002). The role of the business model in capturing value from innovation: evidence from Xerox Corporation's technology spin - off companies. Industrial and Corporate Change, 11(3), 529-555. 
https://doi.org/10.1093/icc/11.3.529

Cinner, J. E., et al. (2012). Comanagement of coral reef social-ecological systems. Proceedings of the National Academy of Sciences, 109(14), 5219-5222. https://doi.org/10.1073/pnas.1121215109

DOOLEY, K. J. (2002). Organizational Complexity. In M. Warner (ed.), International Encyclopedia of Business and Management. London: Thompson Learning.

Ellis, F. (2000). The determinants of rural livelihood diversification in developing countries. Journal of Agricultural Economics, 51(2), 289-302. https://doi.org/10.1111/j.1477-9552.2000.tb01229.x

Fiksel, J. (2003). Designing Resilient, Sustainable Systems. Environmental Science and Technology, 37(23), 5330-5339. https://doi.org/10.1021/es0344819

Fisken, J., \& J. Rutherford (2002). Business models and investment trends in the biotechnology industry in Europe. Journal of Commercial Biotechnology, 8(3), 191. https://doi.org/10.5912/jcb431

Folke, C., et al. (2002). Resilience and sustainable development: building adaptive capacity in a world of transformations. Ambio, 31, 437-440. https://doi.org/10.1579/0044-7447-31.5.437

Folke, C., et al. (2010). Resilience Thinking: Integrating Resilience, Adaptability and $\begin{array}{lllll}\text { Transformability. Ecology and } & \text { Society, }\end{array}$ https://doi.org/10.5751/ES-03610-150420

Forman, J., \& L. Damschroder (2007). Qualitative Content Analysis, in Liva Jacoby, Laura A. Siminoff (ed.) Empirical Methods for Bioethics: A Primer (Advances in Bioethics, Volume 11) Emerald Group Publishing Limited, pp.39-62. https://doi.org/10.1016/S1479-3709(07)11003-7

Gavetti, G., et al. (2007). Fujifilm: A second foundation. Harvard Business School Case, 9-807 137. https://doi.org/10.2139/ssrn.1622888

Gunderson, L. H., et al. (2002). A summary and synthesis of resilience in large-scale systems. Scope-Scientific Committee on Problems of the Environment International Council of Scientific Unions, 60, 249-266.

Hamel, G., \& L. Välikangas (2003). The Quest for Resilience. Harvard Business Review.

Harreld, J. B., et al. (2007). Dynamic capabilities at IBM: Driving strategy into action. California management review, 49(4), 21-43. https://doi.org/10.2307/41166404

Hills, A. (2000). Revisiting Institutional Resilience as a Tool in Crisis Management. Journal of $\begin{array}{llll}\text { Contingencies and Crisis Management, } & \text { 8(2), 109-118. }\end{array}$ https://doi.org/10.1111/1468-5973.00130

Holling, C. S. (1973). Resilience and Stability of Ecological Systems. Annual Review of 
Ecological Systems, 4. https://doi.org/10.1146/annurev.es.04.110173.000245

Holling, C. S. (1996). Engineering resilience vs. ecological resilience. Engineering Within Ecological Constraints, 31-43.

Holling, C. S. (2001). Understanding the Complexity of Economic, Ecological, and Social Systems. Ecosystems, 4, 390-405. https://doi.org/10.1007/s10021-001-0101-5

Hsieh, H.-F., \& S. E. Shannon. (2005). Three approaches to qualitative content analysis. $\begin{array}{llll}\text { Qualitative health } & \text { research, } & 15(9), & 1277-1288 .\end{array}$ https://doi.org/10.1177/1049732305276687

Johnson, D. W. (2015). FUJIFILM'S “MOMENT”: DISRUPTION, ADAPTATION AND HEALTH SYSTEM TRANSFORMATION. 4sight HEALTH. from http://www.4sighthealth.com/fujifilms-moment-disruption-adaptation-and-health-system -transformation/

K.N.C. (2012). How Fujifilm survived - Sharper Focus. The Economist. from https://www.economist.com/schumpeter/2012/01/18/sharper-focus.

Komori, S. (2015). Innovating out of crisis: How Fujifilm survived (and Thrived) as its core business was vanishing. Stone Bridge Press, Inc.

Longstaff, P. H., et al. (2010). Building Resilient Communities: A Preliminary Framework for Assessment. Homeland Security Affairs, VI(3).

May, R. M., et al. (2008). Complex systems: Ecology for bankers. Nature, 451(7181), 893-895. https://doi.org/10.1038/451893a

Ng, D. (2017). How Fujifilm survived the digital age with an unexpected makeover. CHANNEL NEWSASIA. Retrieved from https://www.channelnewsasia.com/news/business/how-fujifilm-survived-the-digital-agewith-an-unexpected-makeove-7626418.

Nyström, M., \& C. Folke (2001). Spatial resilience of coral reefs. Ecosystems, 4(5), 406-417. https://doi.org/10.1007/s10021-001-0019-y

Porter, M. E. (1985). Competitive Advantage. Creating and sustaining superior performance. Free Press, New York.

Reeves, M., et al. (2016). The biology of corporate survival. Harvard Business Review, 94(1), 2.

Schoemaker, P. J. (1991). When and how to use scenario planning: a heuristic approach with illustration. Journal of forecasting, 10(6), 549-564. https://doi.org/10.1002/for.3980100602

Schwartz, P., \& D. Randall (2007) Ahead of the Curve: Anticipating Strategic Surprise. MONITOR_GROUP

Teece, D. J. (2010). Business models, business strategy and innovation. Long Range Planning, 
43(2), 172-194. https://doi.org/10.1002/for.3980100602

Walker, B., \& J. A. Meyers (2004). Thresholds in Ecological and Social-Ecological Systems: a Developing Database. Ecology and Society, 9(2), 3. https://doi.org/10.5751/ES-00664-090203

Walker, et al. (2006). A Handful of Heuristics and Some Propositions for Understanding Resilience in Social-Ecological Systems. Ecology and Society, 11(1), 13. https://doi.org/10.5751/ES-01530-110113

Winter, R., \& R. Fischer (2006). Essential layers, artifacts, and dependencies of enterprise architecture. Enterprise Distributed Object Computing Conference Workshops, 2006. EDOCW'06. 10th IEEE International, IEEE. https://doi.org/10.1109/EDOCW.2006.33

\section{Copyright Disclaimer}

Copyright for this article is retained by the author(s), with first publication rights granted to the journal.

This is an open-access article distributed under the terms and conditions of the Creative Commons Attribution license (http://creativecommons.org/licenses/by/3.0/). 